\title{
Associations of adult measures of childhood growth with breast cancer: findings from the British Women's Heart and Health Study
}

\author{
DA Lawlor,', M Okasha', D Gunnell', G Davey Smith ' and S Ebrahim' \\ 'Department of Social Medicine, University of Bristol, Canynge Hall, Whiteladies Road, Bristol BS8 2PR, UK
}

\begin{abstract}
Since the two components of adult height - leg length and trunk length - are poorly correlated with each other and appear to be influenced by different early life factors, examining their separate influence on breast cancer may provide additional insights into the mechanisms responsible for the positive association between adult height and breast cancer. In a cross-sectional study of 4286 women aged 60-79 years, in whom there were 170 cases of breast cancer, we found total height, leg length and trunk length were all modestly positively and linearly associated with breast cancer. The magnitudes of the associations of leg and trunk length were similar: fully adjusted odds ratio (95\% confidence interval) of breast cancer for a one standard deviation (s.d.) increase in leg length I. I $7(0.98$, I.39) and for a I s.d. increase in trunk length I. I $9(0.99$, I.4I). Self-reported birth weight (available on $33 \%$ of the sample) was positively and linearly associated with breast cancer: fully adjusted odds ratio of breast cancer for a I s.d. increase in birth weight I.30 $(0.93,1.80)$. These associations were all independent of each other and other potential confounding factors and are likely to reflect different mechanisms by which factors operating prenatally and prepubertally influence breast cancer risk. British Journal of Cancer (2003) 89, 8 I-87. doi:I0.I038/sj.bjc.6600972 www.bjcancer.com
\end{abstract} (C) 2003 Cancer Research UK

Keywords: breast cancer; adult height; adult leg length; adult trunk length; arthropometry; early life risk

Ecological studies of breast cancer have shown that geographic variations in incidence and mortality are associated with variations in population height (Barker et al, 1990; Albanes and Taylor, 1990). The majority of cohort studies have found that tall stature is associated with increased cancer risk. The most consistent associations are found for breast cancer, a recent review finding that all but one (Davey Smith et al, 2000) of 24 prospective studies showed a positive association with height (Gunnell et al, 2001).

The underlying mechanisms for the association between tall stature and breast cancer risk are not understood. The association may be explained by factors that jointly influence stature and breast cancer risk. These include hormones such as insulin-likegrowth factor I (IGF-I) (Hankinson et al, 1998; Kaaks et al, 2002), energy intake in childhood (McCay et al, 1939; Hart and Turturro, 1997; Frankel et al, 1998), and also intrauterine growth, reflected by birth weight, which has been found to be positively associated with breast cancer risk (Michels et al, 1996; Stavola et al, 2000; Vatten et al, 2002). Since the two components of adult height - leg length and trunk length - are poorly correlated with each other and appear to be influenced by different early life factors (Gunnell, 2002; Wadsworth et al, 2002), examining their separate associations with breast cancer may provide additional insights into the mechanisms responsible for the association between height and breast cancer. Three case-control studies have reported inconsistent findings in the associations between components of height and breast cancer (Brinkley et al, 1971; Mondina et al, 1992; Swanson et al, 1996). One prospective cohort study found modest associations between both leg length and trunk length (Albanes et al, 1988), whereas a second found an association with leg length

*Correspondence: Dr DA Lawlor; E-mail: d.a.lawlor@bristol.ac.uk Received 21 January 2003; revised 14 March 2003; accepted 14 March 2003 only, but this was based on six cases of breast cancer (Gunnell et al, 1998). The aim of this study is to investigate the associations of self-reported birth weight and adult anthropometric indicators of childhood growth with breast cancer.

\section{METHODS}

\section{Participants}

The British Women's Heart and Health Study comprises 4286 (60\% of those invited to participate) women aged 60-79 years randomly selected from general practitioner lists of 23 British towns. Selection of towns, general practitioners (GPs) and participants was based on the methods used for the British Regional Heart Study of men (Shaper et al, 1981). Ethics committee approvals were obtained for the study and consent to access medical records and to flag the women with the National Health Service Cancer Register (NHSCR) were obtained from the participants. Participants completed a questionnaire and attended a local health centre where a research nurse interview, physical examination and blood sampling were undertaken. General practitioner (primary care) medical records were reviewed for each participant and details of diagnoses of cardiovascular disease, diabetes and cancers were extracted by reviewing written general practice records, hospital letters and computerised medical records. Data were collected between April 1999 and March 2001 and full details of methods have been previously reported (Lawlor et al, 2002).

\section{Measurements}

Standing and seated heights were measured to the nearest millimetre, without shoes, using a Harpenden Stadiometer. Trunk length was calculated as the seated height minus the height of the 
stool $(407 \mathrm{~mm})$. Leg length was taken as the standing height minus the trunk length. Weight was measured in light clothing without shoes to the nearest $0.1 \mathrm{~kg}$ using Soenhle portable scales. Waist circumference was taken as the midpoint between the lower rib and the iliac crest. Hip circumference was taken as the largest circumference below the waist.

Three sources of data were used to determine breast cancer status: (i) women were asked if they had ever been told by a doctor that they had breast cancer and, if so, the date of diagnosis; (ii) diagnoses of breast cancer together with dates were extracted from the general practitioner medical records (including written records, computer records and hospital correspondence); and (iii) all participants were flagged with the National Health Service Central Register (NHSCR), which provided details of cancer registrations. Anyone with a diagnosis of breast cancer from any one of these three sources was considered to be a prevalent case. Flagging of participants with the NHSCR was continuous, and is still ongoing, from the time of the baseline fieldwork (completed in March 2001). We included all cases from the NHSCR that were reported to us by the NHSCR up to November 2002 (the time of the current analyses) and that had been diagnosed prior to the date that the woman attended for baseline study examination. Cases were defined as pre- and postmenopausal based on self-report of age at menopause and the date of first diagnosis of breast cancer obtained from the GP record, cancer register or, if not available from these two sources, self-report $(n=11)$. For women who had had an oophorectomy prior to their natural menopause, the date of the oophorectomy was taken as their date of menopause. For women who had had a hysterectomy without oophorectomy prior to their natural menopause, their age of menopause was assumed to be the median of the cohort -50 years $(n=11$ breast cancer cases), and for women with breast cancer who did not provide details of their age at menopause, their age at menopause was assigned 50 years $(n=3)$. The women were asked to report their birth weight in pounds (lb) and ounces (oz) in the self-completed questionnaire; they were not given the option of providing birth weight in prespecified categories. For comparisons with other studies, the self-reported birth weights were converted from $\mathrm{lb}$ to $\mathrm{kg}$ by multiplying by a factor of 0.4545 .

\section{Statistical analysis}

Pearson's correlation coefficients were used to assess associations between total height and components of height. To illustrate the direction and shape of associations, age-adjusted means and prevalences of breast cancer and possible confounding factors were estimated across quarters of height and each component of height. These were estimated using multiple linear and logistic regression models with the age variable centred around the mean age value. Multiple logistic regression was used to assess the associations of the various anthropometric measures with breast cancer prevalence, with adjustment for potential confounding or intermediary variables. In these models, age, age at menarche, age at menopause, weight, waist-to-hip ratio and birth weight were entered as continuous variables. Osteoporosis (yes, no), hysterectomy and/or oopherectomy (yes, no) adult and childhood social class (I, II, III nonmanual, III manual, IV, V) and smoking (never, ex- and current) were entered as dummy variables. Of the 4286 women, 425 could not be assigned an adult social class and 545 could not be assigned to a childhood social class because they did not provide data on occupation. Although the participants were not specifically asked about unemployment, these women are likely to have been married to unemployed men (for those with missing adult data) and had fathers who were unemployed (for those with missing childhood data). This is consistent with the findings that women without these data on social class were more likely to smoke, more likely to be obese, were shorter and were more likely to have prevalent coronary heart disease than cohort members who provided these data (Lawlor et al, 2002). In the main analysis, women with missing social class data were allocated to social class $\mathrm{V}$, the most deprived group. A sensitivity analysis was conducted in which these women were excluded from the analysis. These results did not differ substantively from the main analyses and have not been presented in this paper. There were missing data on age at menarche $(n=405)$, age at menopause $(n=280)$, smoking $(n=19)$ and osteoporosis $(n=476)$. In all multiple logistic regression models, only those with complete data on all variables $(n=3554)$ included in the fully adjusted model were included in each simpler model. In all analyses, robust standard errors taking into account possible nonindependence between women from the same town were used to estimate confidence intervals.

\section{RESULTS}

The prevalence of breast cancer among women who were invited to take part in the study but did not respond was obtained from GP record reviews - the proportion of general practice recorded breast cancer did not differ between responders and nonresponders (3.1\% (95\% confidence interval $2.6,3.7 \%$ ) vs $2.8 \%$ $(2.2,3.5 \%), P=0.7)$. In total, 170 of the participants had a diagnosis of breast cancer from at least one source, giving an overall prevalence of $4.0 \%(3.4,4.6 \%)$. The majority $(87 \%)$ of these cases were identified from at least two sources. The age distributions of women with cancer identified by each source were similar - mean (standard deviation) age of women with breast cancer identified by self-report 68.5 (5.3), identified by medical record review 68.4 (5.3) and identified by cancer register $68.6(5.3)$. Of the 170 cases, $39(22.9 \%)$ were premenopausal and $131(77.1 \%)$ were postmenopausal.

While both leg length and trunk length were strongly correlated with total height (age-adjusted Pearson's correlation coefficients $0.80(95 \%$ confidence interval $0.78,0.82)$ and $0.76(0.74,0.79)$ respectively), leg length and trunk length were only weakly correlated with each other $(r=0.24(0.21,0.27))$. The weak correlation between the two components of height justifies considering their roles in the association between height and disease outcome separately.

Table 1 shows age-adjusted breast cancer prevalence and other characteristics of the participants across quarter of components of height. Breast cancer prevalence shows a graded linear increase with increasing height, leg length and trunk length. Women with shorter legs were younger at menarche. Both shorter trunk length and shorter leg length appear to be associated with younger age at menopause, although the association with trunk length was more consistent across all four quarters. Current smokers and women with osteoporosis had shorter trunk lengths, but neither smoking nor osteoporosis was associated with leg length. Belonging to a manual social class in both adulthood and childhood was associated with reduced lengths of both components of height, but differences were greater for leg length. Birth weight was positively associated with total height, leg length and trunk length.

Table 2 shows the odds ratios for breast cancer associated with each component of height with adjustment for potential confounding factors; these analyses are based on 145 cases of breast cancer among 3554 women with complete data on all variables included in the fully adjusted model. There was no difference in the prevalence of breast cancer between women with complete data on all variables included in these analyses and all women in the cohort (4.1 vs 4.0\%, $P=0.72)$. After adjustment for age, smoking, weight, waist-to-hip ratio, age at menarche, age at menopause, osteoporosis, adult social class and childhood social class, a 1 s.d. increase in total height was associated with an increased odds of prevalent breast cancer: $1.25(1.04,1.50)$. Both leg length and trunk length were associated with increased odds of prevalent breast 
Table I Age-adjusted means or prevalences (95\% confidence interval) of breast cancer and other characteristics by quartiles of components of height $\left(n=4286^{\mathrm{a}}\right)$

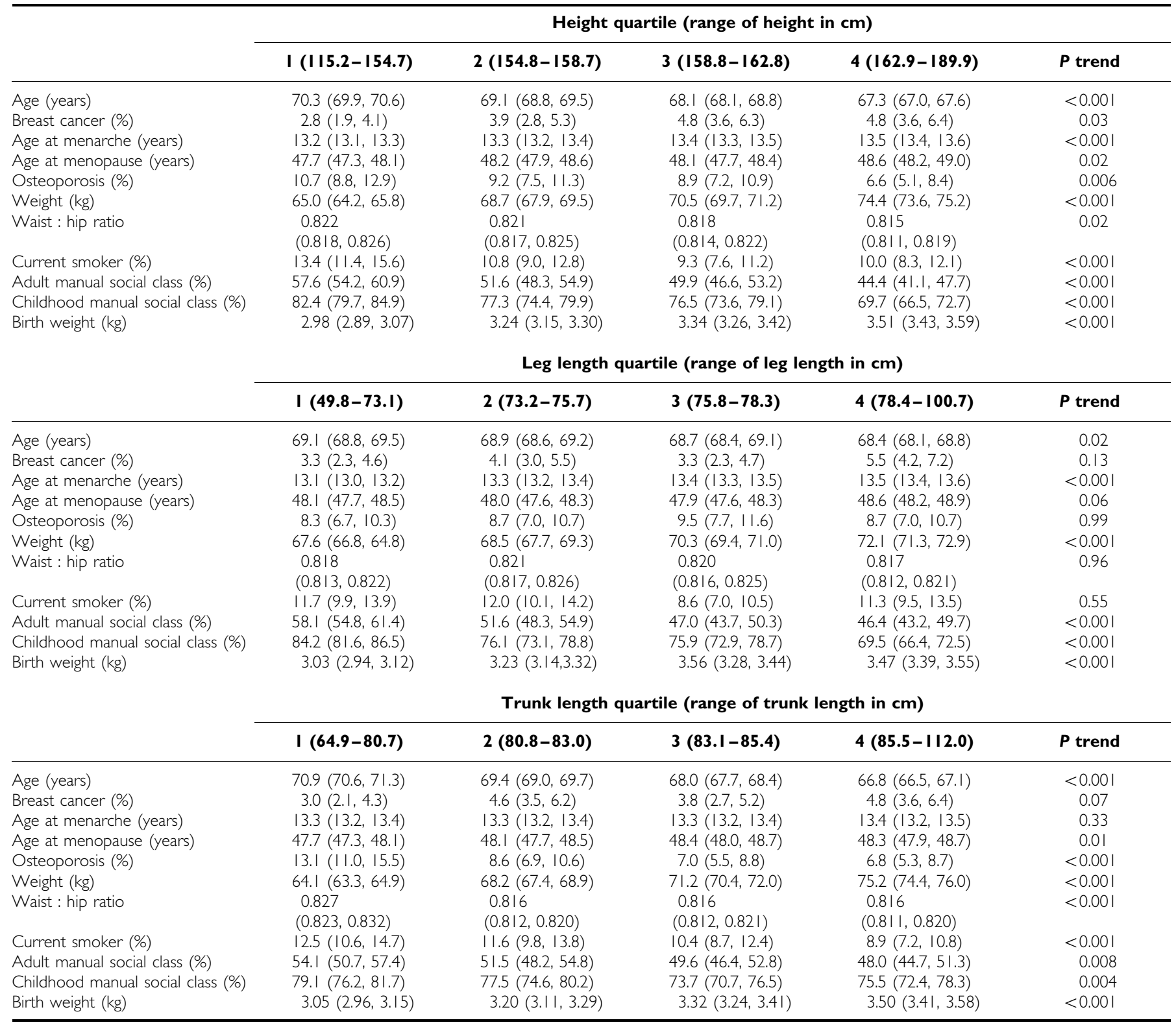

${ }^{a}$ For age at menarche based on 388 I participants; age at menopause 4006 participants; osteoporosis 38 II participants; smoking 4267 participants and birth weight I394 participants.

Table 2 Odds ratios (95\% Confidence intervals) of breast cancer prevalence for a I s.d. increase in height, leg length and trunk length

\begin{tabular}{lccc}
\hline & $\begin{array}{c}\text { Age-adjusted } \\
\text { OR (95\% CI) }\end{array}$ & $\begin{array}{c}\text { Age, lifestyle and } \\
\text { reproductive factor } \\
\text { adjusted }^{\mathbf{a}} \mathbf{O R}(\mathbf{9 5 \%} \mathbf{~ C l})\end{array}$ & $\begin{array}{c}\text { Age, lifestyle, reproductive } \\
\text { factor and lifecourse } \\
\text { socioeconomic position } \\
\text { adjusted }^{\mathbf{b}} \text { OR (95\% CI) }\end{array}$ \\
\hline Height & $1.24(1.04,1.48)$ & $1.25(1.04,1.49)$ & $1.25(1.05,1.50)$ \\
Leg length & $1.15(0.96,1.35)$ & $1.17(0.98,1.39)$ & $1.17(0.98,1.39)$ \\
Trunk length & $1.21(1.00,1.46)$ & $1.19(0.99,1.41)$ & $1.19(0.99,1.41)$ \\
\hline
\end{tabular}

All analyses included in the table are based only on those with complete data for all variables in final model -3554 with I 45 breast cancer cases. $\mathrm{OR}=$ odds ratio $\mathrm{Cl}=$ confidence interval; $|\mathrm{s} . \mathrm{d} .=|$ standard deviation leg length $=4.3 \mathrm{~cm}$, trunk length $=3.6 \mathrm{~cm}$, height $=6.4 \mathrm{~cm}$. ${ }^{a}$ Adjusted for age, smoking, weight, waist-to-hip ratio, age at menarche, age at menopause, hysterectomy/oopherectomy, osteoporosis. ${ }^{\text {b} A d j u s t e d ~ f o r ~ a g e, ~ s m o k i n g, ~ w e i g h t, ~ w a i s t-t o-h i p ~ r a t i o, ~ a g e ~ a t ~ m e n a r c h e, ~ a g e ~ a t ~}$ menopause, hysterectomy/oopherectomy, osteoporosis, adult social class, childhood social class. 
cancer, with the magnitude of the associations being similar for both components of height: fully adjusted odds ratio (95\% confidence interval) for 1 s.d. increase in leg length $1.17(0.98$, $1.39)$ and for 1 s.d. of trunk length $1.19(0.99,1.41)$. Since age at menarche is associated with height and breast cancer, this could potentially act as an important confounder or explanatory factor. However, adjustment for menarcheal age alone did not importantly influence the associations between total height or any of the components of height and breast cancer. With additional mutual adjustment of leg length for trunk length and vice-versa both components of height remained independently associated with breast cancer prevalence: fully adjusted (including trunk length) odds ratio for breast cancer prevalence with 1 s.d. increase in leg length $1.14(0.96,1.37)$ and fully adjusted (including leg length) odds ratio for breast cancer prevalence with 1 s.d. increase in trunk length $1.16(0.96,1.39)$. To assess possible selection bias arising through missing data, we estimated age-adjusted odds ratios for each anthropometric variable in the complete data set. The ageadjusted odds ratios for all women (total height: $1.23(1.05,1.45)$; leg length: $1.14(0.99,1.34)$; and trunk length $1.19(1.01,1.37))$ were similar to those presented in Table 2 for women with complete data included in the multivariable model.

When these associations were examined separately for premenopausal and postmenopausal cancers, there were no associations between height or each component of height and pre-menopausal cancer, but total height, leg length and trunk length were all positively associated with postmenopausal breast cancer (Table 3 ). In these analyses to avoid contamination, we compared women with premenopausal cancer to women without cancer (i.e. we did not include women with postmenopausal cancers in the analysis) and similarly for the analysis concerning postmenopausal cancers the reference group was women with no evidence of breast cancer.

Of the 4286 participants, 1394 (33\%) provided details of their birth weight. There were no differences in prevalent breast cancer between women who provided details of their birth weight and those who did not $(3.7 \%(2.8,4.9 \%)$ vs $4.1 \%(3.5,5.0 \%), P=0.3)$. The mean (s.d.) of self-reported birth weights in this cohort was $3.28(0.80) \mathrm{kg}$. Self-reported birth weight was weakly positively associated with both leg length and trunk length - age-adjusted Pearson's partial correlation coefficient for the association between birth weight and leg length $0.15(0.11,0.19)$ and between birth weight and trunk length $0.16(0.11,0.02)$. In this subgroup of women with data on birth weights, birth weight was positively associated with breast cancer prevalence - age-adjusted odds ratio
(95\% confidence interval) of breast cancer for a 1 s.d. $(0.80 \mathrm{~kg})$ increase in birth weight was $1.33(0.96,1.83)$. The association was only slightly attenuated in fully adjusted models: $1.30(0.93,1.79)$. Additional adjustment for height had little effect: $1.29(0.93,1.79)$.

Adjustment for birth weight did not significantly alter the associations between total height and components of height with breast cancer (Table 4). The fully adjusted (but without birth weight) association between 1 s.d. of height and breast cancer was $1.15(0.83,1.58)$ in this subgroup; addition of birth weight to the model did not change this estimate. Similarly, the odds ratio for the association between leg length and breast cancer was unchanged by adjustment for birth weight. The association between trunk length and breast cancer was slightly attenuated by adjustment for birth weight from $1.20(0.89,1.63)$ to $1.16(0.84$, $1.59)$, but remained positively associated.

When all analyses were repeated using breast cancer data from each of just one of the three sources (cancer register, general practice medical records, self-report), the results were unchanged. Since socioeconomic position is strongly associated with adult height, we repeated the multivariable analyses with different indicators of socioeconomic position in childhood (car access and bedroom sharing) and adulthood (car access and housing tenure) and found no difference to the multivariable results presented in Tables 2, 3 or 4 .

\section{DISCUSSION}

In this study, adult height, leg length, trunk length and birth weight were all modestly and positively associated with breast cancer. The magnitude of the association between total height and breast cancer was similar to that found in a number of prospective cohort studies (Gunnell et al, 2001). In one prospective study that looked at the associations of leg and trunk lengths with breast cancer incidence, the fully adjusted odds ratio comparing the top quarter of leg length to the bottom quarter was $1.6(1.0,2.6)$ and that comparing the top quarter of trunk length to the bottom quarter was $1.3(0.7,2.2)$ (Albanes et al, 1988). When we analyse our data using a similar approach, the two studies are consistent with each other: odds ratio comparing top to bottom quarter of leg length in our study, $2.0(1.2,3.3)$, and comparing top to bottom quarter of trunk length, $1.8(1.0,3.2)$. We found that total height, leg length and trunk length were associated with postmenopausal breast cancers only. However, the small number of premenopausal

Table 3 Odds ratios (ORs) (95\% confidence intervals (Cls)) of breast cancer prevalence for a I s.d. increase in height, leg length and trunk length, with separate results for premenopausal and postmenopausal breast cancer

\begin{tabular}{|c|c|c|c|}
\hline & $\begin{array}{l}\text { Age-adjusted } \\
\text { OR (95\% Cl) }\end{array}$ & $\begin{array}{c}\text { Age, lifestyle and } \\
\text { reproductive factor } \\
\text { adjusted }^{\mathrm{a}} \text { OR }(95 \% \mathrm{Cl})\end{array}$ & $\begin{array}{c}\text { Age, lifestyle, } \\
\text { reproductive } \\
\text { factor and lifecourse } \\
\text { socioeconomic position } \\
\text { adjusted }^{\mathrm{b}} \text { OR }(95 \% \mathrm{Cl})\end{array}$ \\
\hline \multicolumn{4}{|c|}{ Premenopausal cancers, $n=28$} \\
\hline Height & $0.95(0.66,1.37)$ & $0.98(0.68,1.40)$ & $0.99(0.69,1.41)$ \\
\hline Leg length & $0.93(0.65,1.33)$ & $0.94(0.65,1.34)$ & $0.95(0.66,1.46)$ \\
\hline Trunk length & $0.99(0.68,1.42)$ & $1.00(0.69,1.42)$ & $1.00(0.69,1.43)$ \\
\hline \multicolumn{4}{|c|}{ Postmenopausal cancers, $\mathrm{n}=117$} \\
\hline Height & $1.32(1.09,1.61)$ & $1.33(1.09,1.62)$ & $1.31(1.07,1.61)$ \\
\hline Leg length & $1.19(0.99,1.44)$ & $1.23(1.01,1.49)$ & $1.21(1.00,1.48)$ \\
\hline Trunk length & $1.29(1.07,1.55)$ & $1.26(1.04,1.52)$ & $1.23(1.01,1.51)$ \\
\hline
\end{tabular}

All analyses included in the table are based only on those with complete data for all variables in final model. For premenopausal cancers, $n=3437$ with 28 premenopausal breast cancer cases; for postmenopausal cancers, $n=3526$ with 117 postmenopausal breast cancer cases. Women with premenopausal cancers compared to all women without any cancer. Women with postmenopausal cancers compared to all women without any cancer. ${ }^{\text {a,b }}$ See Table 2. 
Table 4 Odds ratios (ORs) (95\% confidence intervals (Cls)) of breast cancer prevalence for a I s.d. increase in height, leg length, trunk length, leg to trunk length ratio with additional adjustment for birth weight

\begin{tabular}{lccc}
\hline & $\begin{array}{c}\text { Age-adjusted } \\
\text { OR (95\% CI) }\end{array}$ & $\begin{array}{c}\text { Fully adjusted } \\
\text { (but without birth weight) }^{\mathbf{a}} \\
\text { OR (95\% CI) }\end{array}$ & $\begin{array}{c}\text { Fully and birth-weight-adjusted } \\
\text { OR (95\% CI) }\end{array}$ \\
\hline Height & $1.17(0.85,1.59)$ & $1.15(0.83,1.58)$ & $1.15(0.83,1.57)$ \\
Leg length & $1.13(0.83,1.56)$ & $1.14(0.83,1.57)$ & $1.14(0.85,1.57)$ \\
Trunk length & $1.23(0.91,1.66)$ & $1.20(0.89,1.63)$ & $1.16(0.84,1.59)$ \\
\hline
\end{tabular}

All analyses included in the table are based only on those with complete data for all variables in final model $n=1250$ with 43 breast cancer cases. I s.d. I standard deviation leg length $=4.3 \mathrm{~cm}$, trunk length $=3.6 \mathrm{~cm}$, height $=6.4 \mathrm{~cm}$. ${ }^{\mathrm{a}}$ Adjusted for age, smoking, weight, waist-to-hip ratio, age at menarche, age at menopause, hysterectomy/oophorectomy, osteoporosis, adult social class, childhood social class. ${ }^{\text {b}}$ Adjusted for all variables included in footnote a and birth weight.

cases meant that these results were imprecise; other studies of the height-breast cancer association have found no difference in the associations between height and pre- and postmenopausal cancers (Gunnell et al, 2001). The magnitude of the association between birth weight and breast cancer in our study is also similar to that of a prospective study (Stavola et al, 2000).

\section{Study limitations}

Our response rate $(60 \%)$ is moderate but the prevalences of GP recorded cases of breast cancer were similar between responders and nonresponders in our study. Height is significantly affected by socioeconomic position, but the social class distribution in our study sample is similar to that found for the 1991 census $(52 \%$ manual social class in British Women's Heart and Health Study $v s$ $55 \%$ older adults in the 1991 census). Further, no indicator of childhood or adulthood social class were found to confound our results. Response bias is, therefore, unlikely to have had an important effect on our results.

Our study is cross-sectional and one of the most important limitations is survivor bias. Breast cancer in the UK is associated with a survival rate of $70 \%$ over 5 years (Coleman et al, 1999). Our study may, therefore, exclude a number of women with the most aggressive form of breast cancer. This would have an important effect on the results if height and the components of height were associated with breast cancer survival. However, the one prospective study that compared the association between both height and breast cancer incidence and mortality found no difference in the magnitude of the association, indicating no effect of height on survival (Tretli, 1989). Reverse causality must also be considered. Women with breast cancer may become shorter in the trunk because of bone or lung metastases or treatment effects on bone integrity, but this would create an inverse relation (not the observed positive association) with breast cancer. Breast cancer is unlikely to have an effect on leg length, and clearly will not affect birth weight. The associations found in our study are all of a similar magnitude to those found in prospective studies (Stavola et al, 2000; Gunnell et al, 2001), suggesting that the cross-sectional nature of our study has not significantly biased our results.

We used self-report of birth weight, which may be inaccurate, although self-reported birth weight is strongly correlated with hospital records among middle-aged and older women (Allen et al, 2002). Women in our study were born between 1919 and 1940 and the mean self-reported birth weight for these women was $3.28 \mathrm{~kg}$ (s.d. 0.80), which is consistent with hospital records of women born between 1923 and 1930 in Hertfordshire, England (3.42 kg, no s.d.) (Fall et al, 1995), and also with women in the 1946 British cohort (3.32 kg, s.d. 0.49 - Dr D Kuh, personal communication). Any misclassification bias is likely to have been nondifferential and will therefore have diluted rather than exaggerated the associations presented.
Explanations for the associations between leg length, trunk length and birth weight with breast cancer

A number of factors may explain the associations between measures of foetal and childhood growth and breast cancer. Genetic factors could explain the association between growth and cancer in two ways. First, genes important in the control of growth may also produce mitogenic proteins. Second, there may be linkage between genes regulating growth and cancer-causing genes. As positive height-cancer associations have been reported in dizygotic twins who were discordant for height, this suggestion is unlikely, although firmer evidence is required from studies of growth-cancer associations in monozygotic twins. Age at menarche is closely related to patterns of growth and final height (Okasha et al, 2002). The timing of exposure to the high levels of sex hormones experienced during puberty may be related to breast cancer risk. However, adjustment for age at menarche did not substantially alter the associations between total height or either component of height and breast cancer.

Leg length and trunk length are only weakly correlated with each other and their associations with breast cancer are independent of each other and other potential confounding factors. This suggests that each component of height is likely to be associated with breast cancer via different mechanisms. Table 5 summarises the possible pathways underlying the growth - breast cancer associations, and these are discussed in more detail below with respect to the specific associations identified in this study.

\section{Leg length}

Leg length is an indicator of prepubertal environmental circumstances; the interruption of growth during childhood results in short leg length (Gunnell, 2002). While a number of childhood factors, such as stress, infection and nutrition, may interrupt growth and hence result in short legs, a detailed analysis of the British 1946 birth cohort found that infant feeding was the most important childhood factor associated with leg length (Wadsworth et al, 2002). Animal studies have shown that energy restriction leads to growth retardation and decreased risk of cancer (McCay et al, 1939; Hankinson et al, 1998), and a study in humans found that lower energy intake in childhood was associated with reduced cancer risk in adulthood (Frankel et al, 1998). The association between energy restriction in childhood and decreased breast cancer risk in adulthood may be mediated via IGF, which plays a fundamental role in somatic growth. Growth hormone affects cellular growth through the actions of IGFs. Serum IGF levels are also affected by diet (Okasha et al, 2002). In children IGF-I levels are positively associated with stature, and during pubertal growth periods IGF-I serum levels can be as high as four times the normal adult concentration. In energy-restricted mice, administration of IGF-I reverses their decreased cancer risk (Petridou et al, 2000). However, in epidemiological studies 
Table 5 Possible pathways underlying growth-breast cancer associations (adapted from Okasha et al., 2002)

Growth as a biomarker for other exposures that influence breast cancer risk

I. In utero exposures

Foetal nutrition is influenced by maternal steroids with greater exposure resulting in greater foetal growth

Exposure to maternal steroids during breast development in utero may increase cancer risk

2. Infections

Chronic infection may stunt growth - in particular trunk length

Absence of childhood infection may make individuals susceptible to infections, which if acquired in later life are associated with cancer risk and may result in an underdeveloped immune function

3. Calorie intake

Lower calorie intake in childhood results in shorter stature and in particular shorter leg length

Lower incidence of cancer in rats fed a calorie-restricted diet

Childhood calorie intake may be related to adult cancer

Calorie intake may also influence growth-promoting hormones (see below)

Growth as a biomarker for biological mediators of risk

4. Cellularity

Greater trunk length may reflect a larger number of breast cells

A larger number of cells increases the risk that one will undergo malignant

transformation

5. Growth-promoting hormones

IGF is related to growth, particularly leg length

IGF is affected by nutritional intake during childhood

IGF is associated with cancer in animal studies although results from

epidemiological studies are inconsistent

6. Oestrogen

Low lifetime exposure to oestrogen will result in shorter trunk length because of osteoporotic collapse

Later age at menarche will result in greater leg length and total height and may be associated with reduced lifetime exposure to oestrogen

Breast cancer risk is associated with increased exposure to oestrogen

inconsistent findings have been reported for the association between IGF-I and breast cancer (Hankinson et al, 1998; Kaaks et al, 2002).

\section{Trunk length}

Childhood illnesses lasting longer than 3 months in any year or leading to a hospital admission are associated with shorter trunk length (Wadsworth et al, 2002), suggesting that the association between longer trunk length and breast cancer prevalence may reflect reduced childhood infections. A lower number of infections in childhood (resulting in longer trunk length) may lead to increased cancer risk in two ways (Gunnell et al, 2001). First, it may leave older children and adults susceptible to infections that, if experienced in later life, carry a greater risk of malignancy. Late childhood infection with Epstein - Barr virus and cytomegalovirus may be implicated in breast cancer aetiology (Richardson, 1997; Touitou et al, 2001). Second, it may lead to an underdevelopment of immune function and hence an increase in cancer risk. It has been shown that risk of lymphoma is increased among individuals from small families and that small family size is, in turn, associated with greater stature (Bonelli et al, 1990; Davey Smith et al, 2000). In the US Nurses Health Study, women who were breastfed as children, and therefore likely to have had fewer childhood infections than those who were not, had a slightly increased risk of breast cancer $1.11(0.88,1.39)$ (Michels et al, 2001), supporting the hypothesis that childhood infections might protect against breast cancer risk. We found that women who shared a bedroom as children (and by implication were therefore, more likely to be exposed to childhood infections) were less likely to have breast cancer: age-adjusted odds ratio ( $95 \%$ confidence interval) compar- ing those who shared a bedroom to those who did not $0.81(0.59$, 1.13), but bedroom sharing did not attenuate the association between trunk length and breast cancer.

Trunk length will also be significantly influenced by lifetime exposure to oestrogen and will be shorter because of osteoporotic collapse in those with low levels of oestrogen exposure. Breast cancer is oestrogen dependent, with risk being lower in those with lower levels of exposure. Thus, the positive association between trunk length and breast cancer may reflect the associations between high levels of lifetime exposure to oestrogen and decreased osteoporosis but increased breast cancer risk.

An alternative explanation for the association between trunk length and breast cancer is that women with larger trunks may have greater breast size. It has been hypothesised that breast size predicts a woman's risk of breast cancer because of increased breast cell numbers, and both chest size (as indicated by bra size) and breast size (as indicated by cup size) have been found to predict breast cancer (Egan et al, 1999). Breast density, a marker of cellularity of the breast, is related to breast cancer (Saftlas et al, 1991), suggesting that associations between measures of breast size and breast cancer may reflect greater numbers of breast cells leading to increased risk.

\section{Birth weight}

The association between birth weight and breast cancer risk most likely reflects intrauterine exposures to maternal hormones that influence both foetal growth and intrauterine development of the mammary gland. Oestrogen would be one plausible hormone since exposures to high levels of intrauterine oestrogen lead to increased foetal size (Trichopoulos, 1990) and indictors of pregnancy oestrogen concentrations have been shown to be associated with breast cancer risk (Ekbom et al, 1992, 1997).

\section{Implications}

The associations between different measures of foetal and childhood growth most likely reflect differing intrauterine and childhood environmental risk factors for breast cancer. These findings highlight the importance of foetal and early life exposures in the aetiology of breast cancer. Further research should concentrate on testing specific hypotheses concerning these associations as outlined in Table 5.

\section{ACKNOWLEDGEMENTS}

The British Women's Heart and Health Study is codirected by Professor Shah Ebrahim, Professor Peter Whincup, Dr Goya Wannamethee and Dr Debbie A Lawlor. We thank Carol Bedford, Alison Emerton, Nicola Frecknall, Karen Jones, Mark Taylor and Katherine Wornell for collecting and entering data, all of the general practitioners and their staff who have supported data collection and the women who have participated in the study.

Contributions: All authors developed the study aim and design. DAL undertook the initial analysis and coordinated writing of the paper. All authors contributed to the final version.

Funding: The British Women's Heart and Health Study is funded by the Department of Health. DA Lawlor is funded by a Medical Research Council/Department of Health training fellowship. M Okasha is funded by the Breast Cancer Campaign. The views expressed in this publication are those of the authors and not necessarily those of any of the funding bodies.

Conflict of interests: None. 


\section{REFERENCES}

Albanes D, Jones DY, Schatzkin A, Micozzi MS, Taylor PR (1988) Adult stature and risk of cancer. Cancer Res 48: $1658-1662$

Albanes D, Taylor PR (1990) International differences in body height and weight and their relationship to cancer incidence. Nutr Cancer 14: 69-77

Allen DS, Ellison GT, dos Santos Silva I, De Stavola BL, Fentiman IS (2002) Determinants of the availability and accuracy of self-reported birth weight in middle-aged and elderly women. Am J Epidemiol 155: 379-384

Barker DJ, Osmond C, Golding J (1990) Height and mortality in the counties of England and Wales. Ann Hum Biol 17: 1-6

Bonelli L, Vitale V, Bistolfi F, Landucci M, Bruzzi P (1990) Hodgkin's disease in adults: association with social factors and age at tonsillectomy. A case-control study. Int J Cancer 45: 423-427

Brinkley D, Carpenter R, Haybittle J (1971) An anthropometric study of women with cancer. Br J Prev Soc Med 25: 65-75

Coleman MP, Babb P, Damecki P, Groscalude P, Hanjos S, Jones J (1999) Cancer survival trends in England and Wales 1971-1995: Deprivation and NHS Region. London: Stationery Office

Davey Smith G, Hart C, Upton M, Hole D, Gillis C, Watt G, Hawthorne V (2000) Height and risk of death among men and women: aetiological implications of associations with cardiorespiratory disease and cancer mortality. J Epidemiol Community Health 54: 97-103

Egan KM, Newcomb PA, Titus-Ernstoff L, Trentham-Dietz A, Baron JA, Willett WC, Stampfer MJ, Trichopoulos D (1999) The relation of breast size to breast cancer risk in postmenopausal women (United States). Cancer Causes Control 10: 115-118

Ekbom A, Hsieh CC, Lipworth L, Adami HQ, Trichopoulos D (1997) Intrauterine environment and breast cancer risk in women: a population-based study. J Natl Cancer Inst 89: $71-76$

Ekbom A, Trichopoulos D, Adami HO, Hsieh CC, Lan SJ (1992) Evidence of prenatal influences on breast cancer risk. Lancet 340: $1015-1018$

Fall CH, Osmond C, Barker DJ, Clark PM, Hales CN, Stirling Y, Meade TW (1995) Fetal and infant growth and cardiovascular risk factors in women. BMJ 310: $428-432$

Frankel S, Gunnell DJ, Peters TJ, Maynard M, Davey Smith G (1998) Childhood energy intake and adult mortality from cancer: the Boyd Orr Cohort Study. BMJ 316: 499-504

Gunnell D (2002) Can adult anthropometry be used as a 'biomarker' for prenatal and childhood exposures? Int J Epidemiol 31: 390-394

Gunnell D, Okasha M, Davey Smith G, Oliver SE, Sandhu J, Holly JMP (2001) Height, leg length, and cancer risk: a systematic review. Epidemiol Rev 23: $313-341$

Gunnell DJ, Davey Smith G, Frankel S, Nanchahal K, Braddon FE, Pemberton J, Peters TJ (1998) Childhood leg length and adult mortality: follow up of the Carnegie (Boyd Orr) Survey of Diet and Health in Prewar Britain. J Epidemiol Community Health 52: $142-152$

Hankinson SE, Willett WC, Colditz GA, Hunter DJ, Michaud DS, Deroo B, Rosner B, Speizer FE, Pollak M (1998) Circulating concentrations of insulin-like growth factor-I and risk of breast cancer. Lancet 351: 1393 1396

Hart RW, Turturro A (1997) Dietary restrictions and cancer. Environ Health Perspect 105: 989-992

Kaaks R, Lundin E, Rinaldi S, Manjer J, Biessy C, Soderberg S, Lenner P, Janzon L, Riboli E, Berglund G, Hallmans G (2002) Prospective study of
IGF-I, IGF-binding proteins, and breast cancer risk, in northern and southern Sweden. Cancer Causes Control 13: 307-316

Lawlor DA, Ebrahim S, Davey Smith G (2002) Socioeconomic position in childhood and adulthood and insulin resistance: cross sectional survey using data from the British Women's Heart and Health Study. BMJ 325: $805-807$

McCay CM, Maynard LA, Sperling G, Barnes LL (1939) Retarded growth, life span, ultimate body size and age changes in the albino rat after feeding diets restricted in calories. J Nutr 18: $1-13$

Michels KB, Trichopoulos D, Robins JM, Rosner BA, Manson JE, Hunter DJ, Colditz GA, Hankinson SE, Speizer FE, Willett WC (1996) Birthweight as a risk factor for breast cancer. Lancet 348: $1542-1546$

Michels K, Trichopoulos D, Rosner B, Hunter D, Colditz G, Hankinson S, Speizer F, Willett W (2001) Being breastfed in infancy and breast cancer incidence in adult life: results from two nurses' health studies. Am J Epidemiol 153: 275-283

Mondina R, Borsellino G, Poma S, Baroni M, Di Nubila B, Saachi P (1992) Breast carcinoma and skeletal formation. Eur J Cancer 28A: 1068-1070

Okasha M, Gunnell D, Holly J, Davey Smith G (2002) Childhood growth and adult cancer. Best Pract Res Clin Endocrinol Metab 16: 225-241

Petridou E, Papadiamantis Y, Markopoulos C, Spanos E, Dessypris N, Trichopoulos D (2000) Leptin and insulin growth factor I in relation to breast cancer (Greece). Cancer Causes Control 11: 383-388

Richardson A (1997) Is breast cancer caused by late exposure to a common virus? Med Hypotheses 48: $491-497$

Saftlas AF, Hoover RN, Brinton LA, Szklo M, Olson DR, Salane M, Wolfe JN (1991) Mammographic densities and risk of breast cancer. Cancer 67: $2833-2838$

Shaper AG, Pocock SJ, Walker M, Cohen NM, Wale CJ, Thomson AG (1981) British Regional Heart Study: cardiovascular risk factors in middle-aged men in 24 towns. BMJ 283: $179-186$

Stavola BL, Hardy R, Kuh D, Silva IS, Wadsworth M, Swerdlow AJ (2000) Birthweight, childhood growth and risk of breast cancer in a British cohort. Br J Cancer 83: $964-968$

Swanson CA, Coates RJ, Schoenberg JB, Malone KE, Gammon MD, Stanford JL, Shorr IJ, Potischman NA, Brinton LA (1996) Body size and breast cancer risk among women under age 45 years. Am J Epidemiol 143: $698-706$

Touitou R, Bonnet-Duquenoy M, Joab I (2001) Association of Epstein - Barr virus with human mammary carcinoma. Pros and cons. Dis Markers 17: $163-165$

Tretli S (1989) Height and weight in relation to breast cancer morbidity and mortality. A prospective study of 570,000 women in Norway. Int J Cancer 44: $23-30$

Trichopoulos D (1990) Hypothesis: does breast cancer originate in utero? Lancet 335: $939-940$

Vatten LJ, Maehle BO, Lund Nilsen TI, Tretli S, Hsieh CC, Trichopoulos D, Stuver SO (2002) Birth weight as a predictor of breast cancer: a casecontrol study in Norway. Br J Cancer 86: 89-91

Wadsworth MEJ, Hardy RJ, Paul AA, Marshall SF, Cole TJ (2002) Leg and trunk length at 43 years in relation to childhood health, diet and family circumstances; evidence from the 1946 national birth cohort. Int $J$ Epidemiol 31: $383-390$ 